\title{
Comparing unplanned and potentially planned home deaths: a population-based cross-sectional study
}

\author{
Camilla Kjellstadli ${ }^{1,2^{*}}$ (D), Bettina Sandgathe Huseb $\varnothing^{2,3}$, Hogne Sandvik ${ }^{4}$, Elisabeth Flo ${ }^{5}$ and Steinar Hunskaar ${ }^{1,4}$
}

\begin{abstract}
Background: There is little research on number of planned home deaths. We need information about factors associated with home deaths, but also differences between planned and unplanned home deaths to improve end-of-life-care at home and make home deaths a feasible alternative. Our aim was to investigate factors associated with home deaths, estimate number of potentially planned home deaths, and differences in individual characteristics between people with and without a potentially planned home death.
\end{abstract}

Methods: A cross-sectional study of all decedents in Norway in 2012 and 2013, using data from the Norwegian Cause of Death Registry and National registry for statistics on municipal health and care services. We defined planned home death by an indirect algorithm-based method using domiciliary care and diagnosis. We used logistic regressions models to evaluate factors associated with home death compared with nursing home and hospital; and to compare unplanned home deaths and potentially planned home deaths.

Results: Among 80,908 deaths, 12,156 (15.0\%) were home deaths. A home death was most frequent in 'Circulatory diseases' and 'Cancer', and associated with male sex, younger age, receiving domiciliary care and living alone. Only 2.3\% of home deaths were from 'Dementia'. In total, $41.9 \%$ of home deaths and $6.3 \%$ of all deaths were potentially planned home deaths. Potentially planned home deaths were associated with higher age, but declined in ages above 80 years for people who had municipal care. Living together with someone was associated with more potentially planned home deaths for people with municipal care.

Conclusion: There are few home deaths in Norway. Our estimations indicate that even fewer people than anticipated have a potentially planned home death.

Keywords: Home death, Place of death, Death/epidemiology, Death/statistics and numerical data, Death/classification, Cross-sectional studies, Cause of death, Terminal care, Registries, Retrospective studies

\section{Introduction}

Most people wish to spend their last days of life in their own home and die at home [1]. Despite this, the proportion of home deaths in Western countries continues to decline [2]. Exceptions include Canada, the UK and the US, where home deaths have increased the last 15 to 25 years due to implementation of end-of-life programs

\footnotetext{
* Correspondence: camilla.kjellstadli@uib.no

${ }^{1}$ Research Group for General Practice, Department of Global Public Health and Primary Care, University of Bergen, PO box 7804, N-5018 Bergen, Norway ${ }^{2}$ Centre for Elderly and Nursing Home Medicine, Department of Global Public Health and Primary Care, University of Bergen, PO box 7804, N-5018 Bergen, Norway

Full list of author information is available at the end of the article
}

and policy changes [2-4]. Home deaths increased from $19.3 \%$ in 1994 to $29.5 \%$ in 2004 in Canada; from $18.3 \%$ in 2004 to $20.8 \%$ in 2010 in the UK; and from $30.7 \%$ in 2000 to $33.5 \%$ in 2009 in Medicare beneficiaries aged 66 years and older in the US [2-4].

In Norway, home deaths have been declining, with only $14.3 \%$ of deaths taking place at home in $2015[5,6]$. This is low compared with many other Western countries [7-16]. While home death is not desirable or possible for everyone, we need to know more about who dies at home and influencing factors in order to meet people's preference of dying at home, as well as inform and improve policies. While we know the total number

(c) The Author(s). 2018 Open Access This article is distributed under the terms of the Creative Commons Attribution 4.0 International License (http://creativecommons.org/licenses/by/4.0/), which permits unrestricted use, distribution, and reproduction in any medium, provided you give appropriate credit to the original author(s) and the source, provide a link to the Creative Commons license, and indicate if changes were made. The Creative Commons Public Domain Dedication waiver (http://creativecommons.org/publicdomain/zero/1.0/) applies to the data made available in this article, unless otherwise stated. 
of home deaths, this does not describe the proportion of people who wished to die at home or the number of deaths that were planned or facilitated to take place at home. We cannot use registry data to estimate people's preferences, but we can differentiate sudden, unplanned home deaths from home deaths where health and care service utilisation implies that resources were allocated to facilitate a home death.

In this study, our aim was first to describe factors associated with home deaths in Norway, and compare them with deaths in other locations. Secondly, we aimed to estimate how many home deaths may have been planned. Lastly, we wanted to analyse differences in individual characteristics between people where home deaths may have been planned, and people where home death did not appear to have been planned.

\section{Method}

\section{Data source}

We linked data from the Norwegian Cause of Death Registry (NCoDR) and National registry for statistics on municipal health and care services (IPLOS) covering all 83,434 deaths in Norway in 2012 and 2013. Individuals with missing information about place of death or sex $(n=2526)$ were excluded. The final study sample comprised 80,908 individuals.

Information on causes and place of death are registered in NCoDR [17]. In Norway, the doctor who examines the dead body completes the death certificate. This could be the treating general practitioner or institutional doctor, but also a doctor on night duty. The document is sent to the local county court/police, then to the Chief Municipal Medical Officer, before reaching NCoDR. The registry encompasses all residents, irrespective of whether they die in Norway or abroad, and since 2012 also information on deaths for non-residents. NCoDR has a high degree of coverage and completeness, with medical information on more than $98 \%$ of all deaths. Three quality assessments have ranked NCoDR in the second best group with "medium" and "medium-high" quality respectively, and lastly in the best group regarding quality. In all these three studies, the extensive use of unspecific codes served to lower the score. Few validation studies have been conducted [17].

IPLOS is a national registry for statistics on municipal health and care services. Since 2007 it has been the main data source for Norwegian municipal health and care statistics. It is compulsory for municipalities to register information on all persons who apply for or receive municipal health and care services, describing the person's resources, need of assistance and services provided. Hospital admissions are also registered, but not used here due to poor data quality. Updates are continuously registered, and sent to the register annually. Data quality is assessed by comparison with information in other official statistics (KOSTRA - Municipality-State-Reporting) and reports returned to the municipalities $[18,19]$.

\section{Outcome measures}

NCoDR provided information regarding cause of death, place of death, age, sex and place of residence (municipality population and centrality). IPLOS provided information regarding municipal services and household. We divided place of death into four categories: home; nursing home; hospital; other (abroad, under transportation to hospital, other). Cause of death was given by the European Shortlist for Causes of Death (EU Shortlist) [20]. Persons missing cause of death, with diagnoses removed due to privacy or with cause of death main diagnosis groups with a frequency of less than $5 \%$ of all deaths were labelled "other". We grouped cause of death into eight categories: 'Infectious/parasitic'; 'Symptoms/ signs/ill-defined'; 'External'; 'Cancer' (including uncertain malignancy potential); 'Dementia'; 'Circulatory'; 'Respiratory'; 'Other'. Age at time of death was divided into seven groups $(0-39,40-49,50-59,60-69,70-79,80-$ $89,90+$ years). Municipality centrality was defined as a municipality's geographic location in relation to a centre with important central functions, where 0 is least central (rural) and 3 is most central (urban) [21]. Domiciliary care was coded 'yes' if an individual received practical help or home nursing at any time 0-90 days before death. Nursing home was coded 'yes' if an individual had a stay of any duration in a nursing home or rehabilitation facility 0-90 days before death. Individuals residing in assisted living accommodations with separate apartments were coded as living alone by IPLOS, while individuals in long-term institutional care were coded as cohabiting [18].

\section{Planned and unplanned home deaths}

We created an algorithm to estimate potentially planned and unplanned home deaths (Fig. 1). A home death was defined as unplanned if a person did not receive domiciliary care during the last ninety days before death or if a person who died at home with domiciliary care had cause of death 'Symptoms/signs/ill-defined'. 'Symptoms/ signs/ill-defined' were labelled unplanned, since people who have a planned home death would most likely have a known diagnosis of life-threatening disease later appearing as underlying cause of death in the death certificate; as opposed to people dying at home suddenly, but not unexpectedly of an unspecific cause. We defined a home death as potentially planned if a person had domiciliary care and a cause of death among the most likely diagnoses to receive palliative care. These were according to the EU Shortlist: 'Cancer' (2.), 'Heart disease' (7.1.2/7.1, 7.2.2, 7.4), 'Chronic pulmonary disease' (8.3.2), 


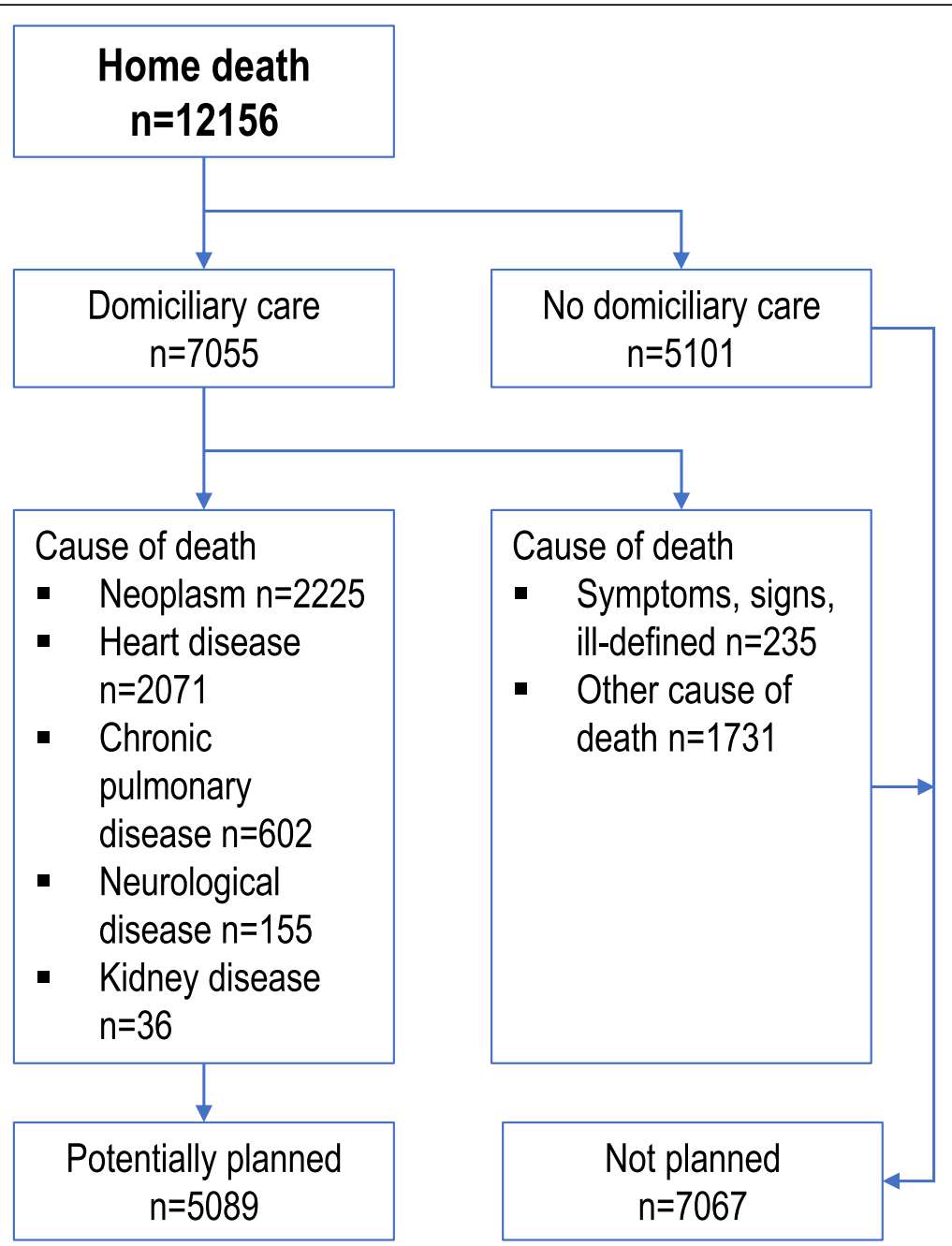

Fig. 1 Algorithm for potentially planned and unplanned home deaths

'Kidney disease' (12.1) and 'Neurological disease' (6.1, 6. $3)[20,22]$. Because the majority of people with dementia die in nursing homes, cause of death from 'Dementia' was not included [23]. The remaining home deaths were categorised as unplanned. The age group 0-39 years was given a lower detail level for cause of death than older age groups due to privacy. Cause of death was divided into six categories according to diagnoses most likely to receive palliative care: 'Cancer'; 'Circulatory'; 'Respiratory'; 'Kidney'; 'Neurological'; 'Other'.

\section{Analyses}

We used frequency tables and Pearson Chi-square for comparisons. Multinomial logistic regression was used to compare death at home, in nursing home and hospital. Independent variables were sex, age, cause of death, municipality centrality, municipality population and domiciliary care. We did a similar analysis including type of household as explanatory variable in a subpopulation of people who received municipal care at any time (registered in IPLOS). Results are presented as adjusted relative risk ratios (RRRs) with 95\% confidence intervals $(\mathrm{CI})$ and $p$-values. xWe used logistic regression to compare potentially planned and unplanned home deaths. Independent variables were sex, age, municipality population, municipality centrality and nursing home stay (model 1). We did a separate analysis for people who received municipal care at any time (registered in IPLOS) with household as an explanatory variable (model 2). Unadjusted and adjusted odds ratios (ORs) with 95\% CI and p-values are presented. Significance was accepted at the $5 \%$ level $(p<$ $0.05)$ for all analyses. Analyses were conducted with STATA 14 (Stata Corp, College Station, TX). 


\section{Results}

\section{Describing the population}

Among 80,908 deaths 12,156 (15.0\%) were classified as home deaths. In total, more women died, with the majority $(56.5 \%)$ dying in nursing homes (Table 1 ). While $18.1 \%$ of all men died at home, only $12.2 \%$ of all women died at home.

Absolute number of home deaths was higher in the older age groups. However, within each age group, home death was more frequent for younger persons (Fig. 2). In people $0-69$ years, $26.5 \%$ died at home, $19.7 \%$ in a nursing home, $44.6 \%$ in a hospital and $9.2 \%$ in other locations. Only $11.8 \%$ of people 70 years or older died at home, while $56.8 \%$ died in a nursing home, $30.1 \%$ in a hospital and $1.3 \%$ in other locations. The most common causes of death were 'Circulatory diseases', 'Cancer,' 'Respiratory diseases,' Infectious diseases' and 'Dementia' (Table 1). 'Circulatory diseases' (34.9\%) and 'Cancer' (21.8\%) were also the most frequent causes of death within the home death group, while only $2.3 \%$ were from 'Dementia'.

A large proportion of deaths had missing information regarding household, largely reflecting people who never received municipal care (Table 1). For those who had services at any time, people living alone (14.2\%) died at home more often than those living with others (9.5\%). In total, $11.6 \%$ had a nursing home stay and $58.0 \%$ received domiciliary care in the last 90 days before dying at home. Of all persons who had a nursing home stay in the last 90 days before death, 3.0\% died at home, while $17.9 \%$ of those receiving domiciliary care died at home.

\section{Comparing home deaths with deaths in nursing homes and hospitals}

Multinomial regression showed that women had a lower relative risk than men for dying at home compared with nursing home (Table 2). We found an age gradient with more home deaths in younger age groups, except for people aged 90 years or older who had a higher relative risk for dying at home than in a hospital, but highest relative risk of dying in a nursing home. People who died from 'Cancer' and 'Respiratory disease' had lower relative risk of home death than 'Circulatory disease' compared with nursing home and hospital. People with 'Dementia' had higher relative risk of dying in nursing homes than home, but lower relative risk of dying in hospitals. Recipients of domiciliary care had higher relative risk of dying at home than in nursing homes or hospitals. A similar regression analysis with only persons who at any time had received municipal care (registered in IPLOS), including household as independent variable, did not alter main findings, but showed that people living with others had lower relative risk of home death compared with death in nursing home (RRR 0.77, 95\% CI 0.73, 0. 82) and hospital (RRR 0.90, 95\% CI 0.87, 0.94).

\section{Comparing potentially planned and unplanned home deaths}

According to our algorithm for estimating potentially planned and unplanned home deaths (Fig. 1), 56.1\% of home deaths and $8.4 \%$ of all deaths were potentially planned home deaths when we included everyone with domiciliary care but not 'Symptoms/signs/ill-defined' causes of death. In the full algorithm, including cause of death, $41.9 \%$ of home deaths and $6.3 \%$ of all deaths were potentially planned home deaths. Men had a higher proportion of both potentially planned and unplanned home deaths than women (Table 3). In people aged 50 years or older $44.5 \%$ of home deaths were potentially planned, but only $15.7 \%$ in those younger than 50 years. Living alone was more frequent in both potentially planned and unplanned home deaths, but more than half of unplanned home deaths had missing information regarding household, making comparisons uncertain. While $84.0 \%$ of 'Cancer' home deaths were potentially planned, this constituted only $10.2 \%$ of all 'Cancer' deaths. The proportion of potentially planned home deaths among all home deaths and total number of deaths for each diagnosis were $76.4 \%$ and $8.5 \%$ in 'Neurological disease', $69.2 \%$ and $7.4 \%$ in 'Renal disease', $63.2 \%$ and $7.3 \%$ in 'Respiratory disease' and $48.8 \%$ and 8. $3 \%$ in 'Circulatory disease', respectively. Moreover, $72.1 \%$ of all home deaths and $12.9 \%$ of all deaths were potentially planned in recipients of domiciliary care.

Table 4 compares two regression models of potentially planned versus unplanned home deaths. In model 1, including all home deaths, women had higher odds than men for having a potentially planned home death, but in model 2, which was restricted to include people who at any time had received municipal care, women had lower odds for having a potentially planned home death. Higher age was associated with more potentially planned home deaths, but in model 2 ages 60-79 years had the highest odds, with declining odds in older age groups. Municipalities with less than 50,000 inhabitants were consistently associated with more potentially planned home deaths, of which municipalities with 500110,000 inhabitants had the highest odds. A nursing home stay during the last 90 days before death was associated with higher odds for a potentially planned home death in model 1 , but had lower odds in model 2. Living together with someone increased the odds for a potentially planned home death in model 2 .

\section{Discussion}

\section{Main findings}

This population-based registry study showed that home death in Norway was most frequent in 'Circulatory disease' and 'Cancer', and associated with male 
Table 1 Distribution of sociodemographic factors and municipal healthcare services by place of death in Norway 2012-2013.*

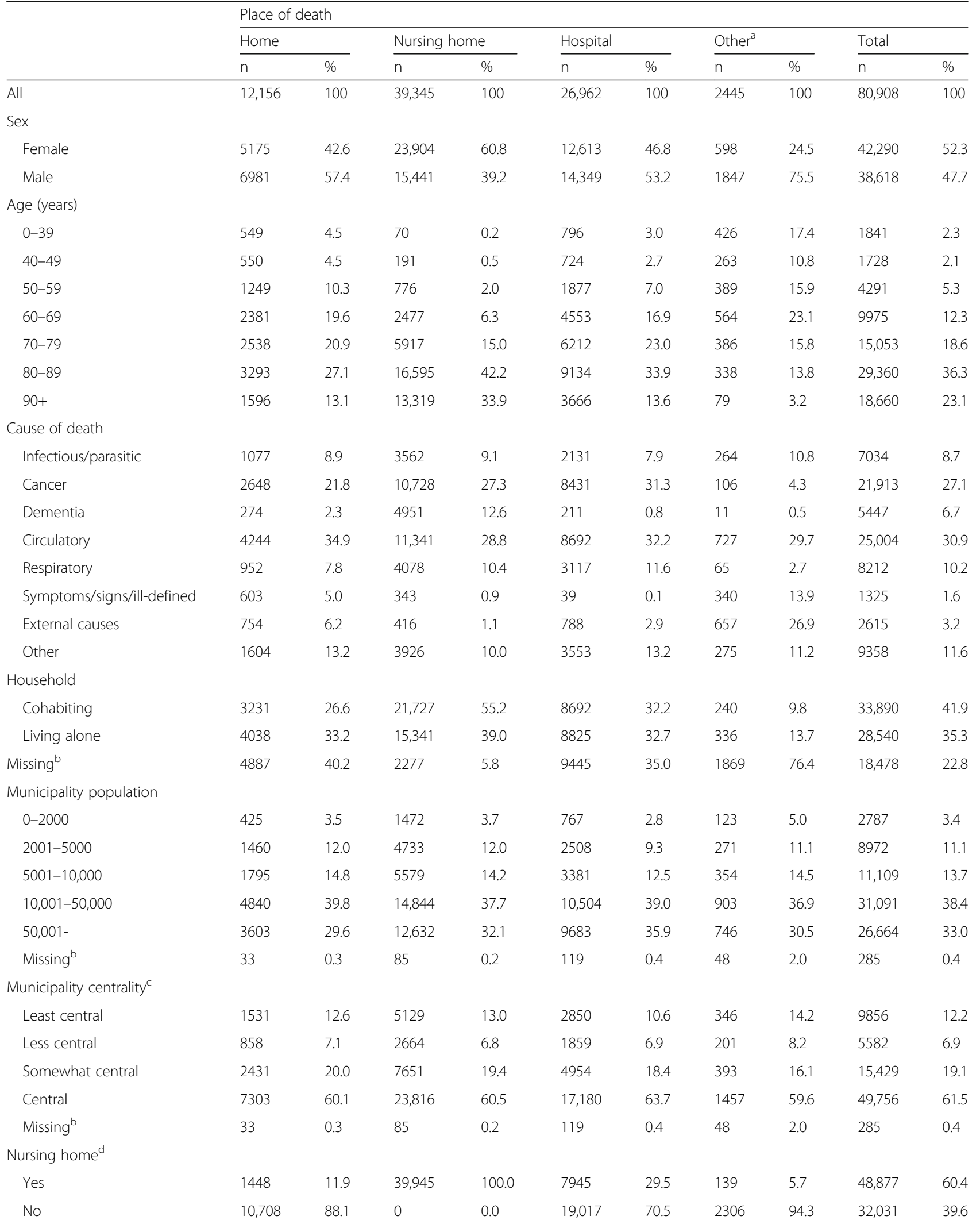


Table 1 Distribution of sociodemographic factors and municipal healthcare services by place of death in Norway 2012-2013.* (Continued)

\begin{tabular}{|c|c|c|c|c|c|c|c|c|c|c|}
\hline & \multicolumn{10}{|c|}{ Place of death } \\
\hline & \multicolumn{2}{|c|}{ Home } & \multicolumn{2}{|c|}{ Nursing home } & \multicolumn{2}{|c|}{ Hospital } & \multicolumn{2}{|c|}{ Other $^{a}$} & \multicolumn{2}{|l|}{ Total } \\
\hline & $n$ & $\%$ & $n$ & $\%$ & $n$ & $\%$ & $n$ & $\%$ & $\bar{n}$ & $\%$ \\
\hline \multicolumn{11}{|c|}{ Domiciliary care $^{d}$} \\
\hline Yes & 7055 & 58.0 & 16,455 & 41.8 & 15,456 & 57.3 & 479 & 19.6 & 39,445 & 48. \\
\hline No & 5101 & 42.0 & 22,890 & 58.2 & 11,506 & 42.7 & 1966 & 80.4 & 41,463 & 51. \\
\hline
\end{tabular}

*Pearson chi-square test: $p<0.001$ for all categories

${ }^{a}$ Other place of death includes abroad, under transportation to hospital, other specified

${ }^{\mathrm{b}}$ Not included in statistical analysis

${ }^{c}$ Classification based on geographical distance to centre with higher functions

${ }^{\mathrm{d}}$ Service any time in the period 0-90 days before death

sex, younger age, receiving domiciliary care and living alone. In total, $41.9 \%$ of home deaths and $6.3 \%$ of all deaths were potentially planned. Potentially planned home deaths were associated with higher age, but declined in ages above 80 years for people who had municipal care. Living together with someone was associated with more potentially planned home deaths for people with municipal care.

\section{Strengths and limitations}

To our knowledge, this is the first study to estimate number of potentially planned home deaths by using population-based registry data. The use of routinely collected data, minimises the burden on patients and caregivers, associated with primary data collection in end-of-life care context [24]. The use of death certificates is similar across countries and comparable. NCoDR provides cause of death for more than $98 \%$ of all deaths in Norway, but has high use of unspecific cause of death codes increasing the risk of misclassification. Additionally, few diagnoses are verified by autopsy [17]. The study accounts for domiciliary care and nursing home admissions prior to death, but it is a limitation that we do not have information regarding hospital admissions. A methodological limitation is that we have no exact data on planned home deaths, but use an indirect approach by an algorithm. However, there is no registry based information source available as an alternative. A limitation for some analyses is that information regarding whether a person lived alone or together with others was only available for people who had received municipal care. Our definition of a potentially planned home death may also have led to deaths from acute illness being classified as potentially planned. Moreover, we cannot exclude that persons with other

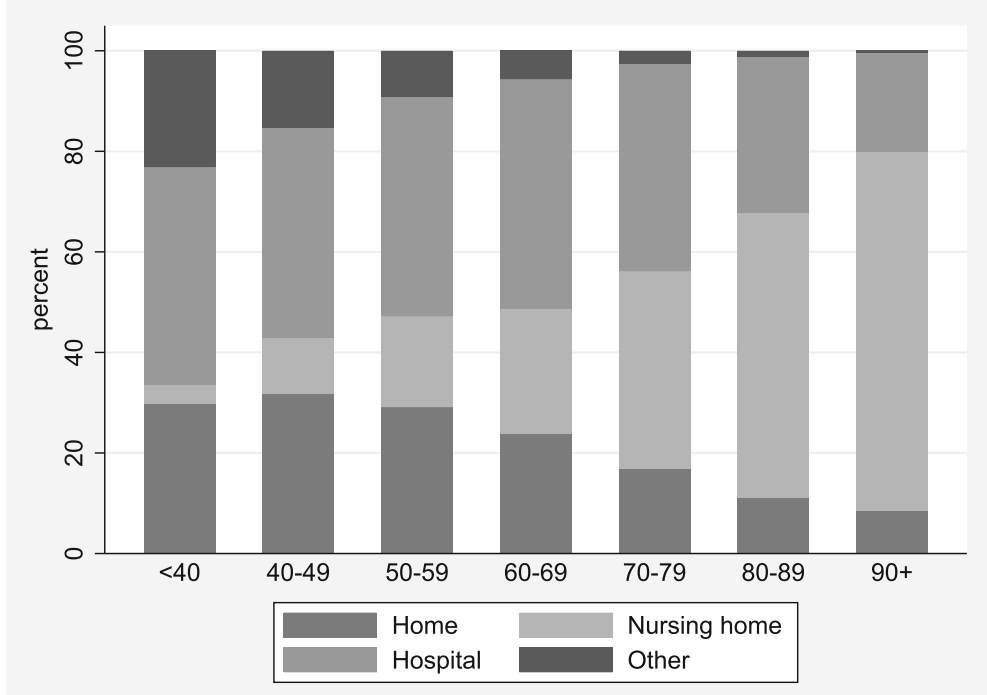

Fig. 2 Distribution of place of death by age groups 
Table 2 Adjusted relative risk ratio (RRR) for death at home versus nursing home, and home versus hospital ${ }^{\mathrm{a}}$

\begin{tabular}{|c|c|c|c|c|c|c|}
\hline & \multicolumn{3}{|c|}{ Home versus nursing home $^{a}$} & \multicolumn{3}{|c|}{ Home versus hospital $^{a}$} \\
\hline & Adjusted RRR & $\mathrm{Cl}$ & $\mathrm{p}$ & Adjusted RRR & $\mathrm{Cl}$ & $\mathrm{p}$ \\
\hline \multicolumn{7}{|l|}{ Sex } \\
\hline Female & 0.67 & $0.64,0.71$ & $<0.001$ & 0.97 & $0.93,1.02$ & 0.223 \\
\hline Male & Ref. & & & Ref. & & \\
\hline \multicolumn{7}{|l|}{ Age } \\
\hline $0-39$ & 49.76 & $38.34,64.58$ & $<0.001$ & 2.21 & $1.94,2.51$ & $<0.001$ \\
\hline $40-49$ & 19.77 & $16.55,23.61$ & $<0.001$ & 2.61 & $2.31,2.96$ & $<0.001$ \\
\hline $50-59$ & 11.71 & $10.55,12.99$ & $<0.001$ & 2.38 & $2.18,2.60$ & $<0.001$ \\
\hline $60-69$ & 7.20 & $6.68,7.75$ & $<0.001$ & 1.91 & $1.78,2.04$ & $<0.001$ \\
\hline $70-79$ & 2.71 & $2.55,2.89$ & $<0.001$ & 1.32 & $1.24,1.41$ & $<0.001$ \\
\hline $80-89$ & Ref. & & & Ref. & & \\
\hline $90+$ & 0.55 & $0.52,0.59$ & $<0.001$ & 1.11 & $1.03,1.19$ & 0.006 \\
\hline \multicolumn{7}{|l|}{ Cause of death } \\
\hline Infectious and parasitic diseases & 0.95 & $0.88,1.04$ & 0.267 & 1.03 & $0.95,1.12$ & 0.461 \\
\hline Cancer & 0.22 & $0.21,0.24$ & $<0.001$ & 0.48 & $0.45,0.51$ & $<0.001$ \\
\hline Dementia & 0.23 & $0.20,0.26$ & $<0.001$ & 3.18 & $2.64,3.82$ & $<0.001$ \\
\hline Circulatory & Ref. & & & Ref. & & \\
\hline Respiratory & 0.51 & $0.47,0.56$ & $<0.001$ & 0.60 & $0.55,0.65$ & $<0.001$ \\
\hline Symptoms/signs/ill-defined & 3.84 & $3.29,4.48$ & $<0.001$ & 32.21 & $23.22,44.71$ & $<0.001$ \\
\hline External causes & 1.92 & $1.66,2.21$ & $<0.001$ & 1.55 & $1.38,1.74$ & $<0.001$ \\
\hline Other & 0.58 & $0.54,0.63$ & $<0.001$ & 0.76 & $0.71,0.82$ & $<0.001$ \\
\hline \multicolumn{7}{|c|}{ Municipality population } \\
\hline $0-2000$ & 1.11 & $0.97,1.28$ & 0.135 & 1.67 & $1.45,1.93$ & $<0.001$ \\
\hline $2001-5000$ & 1.13 & $1.03,1.24$ & 0008 & 1.73 & $1.58,1.93$ & $<0.001$ \\
\hline $5001-10,000$ & 1.11 & $1.02,1.20$ & 0.014 & 1.54 & $1.42,1.66$ & $<0.001$ \\
\hline $10,001-50,000$ & 1.06 & $1.00,1.13$ & 0.033 & 1.30 & $1.23,1.37$ & $<0.001$ \\
\hline $50,001-$ & Ref. & & & Ref. & & \\
\hline \multicolumn{7}{|l|}{ Municipality centrality } \\
\hline Least central & 0.95 & $0.87,1.03$ & 0.227 & 0.94 & $0.86,1.03$ & 0.198 \\
\hline Less central & 1.07 & $0.97,117$ & 0.190 & 0.90 & $0.82,0.99$ & 0.024 \\
\hline Somewhat central & 1.02 & $0.96,1.09$ & 0.465 & 1.01 & $0.95,1.07$ & 0.839 \\
\hline Central & Ref. & & & Ref. & & \\
\hline \multicolumn{7}{|l|}{ Domiciliary care } \\
\hline Yes & 2.70 & $2.58,2.83$ & $<0.001$ & 1.35 & $1.29,1.42$ & $<0.001$ \\
\hline No & Ref. & & & Ref. & & \\
\hline
\end{tabular}

${ }^{a}$ Multinomial logistic regression with place of death as dependent variable. Number of observations 78,226

diagnoses than included in our definition may have had planned home deaths.

\section{Few potentially planned home deaths}

Our data cannot give information regarding a person's preference for dying at home. However, we will argue that our estimation of potentially planned home deaths in Norway is a valid indication. Planned home death is not feasible without the support of domiciliary care and not probable when cause of death is unknown. Even if there is no preference of dying at home, domiciliary care in itself signals facilitation of more time at home and increases the probability of dying at home [25]. Thus, the highest proportion of home deaths that was not random, and could potentially have been planned, was $56.1 \%$ or $8.4 \%$ of all deaths in our model. However, it is likely that 
Table 3 Comparing potentially planned home deaths with unplanned home deaths and all deaths ${ }^{a}$

\begin{tabular}{|c|c|c|c|c|c|c|c|}
\hline & \multicolumn{2}{|c|}{$\begin{array}{l}\text { Potentially planned } \\
\text { home death }\end{array}$} & \multicolumn{2}{|c|}{$\begin{array}{l}\text { Unplanned } \\
\text { home death }\end{array}$} & \multirow[b]{2}{*}{$p$} & \multicolumn{2}{|c|}{ All deaths } \\
\hline & $\mathrm{n}$ & $\%$ & $\mathrm{n}$ & $\%$ & & $n$ & $\%$ \\
\hline All & 5089 & 100 & 7067 & 100 & & 80,908 & 100 \\
\hline Sex & & & & & $<0.001$ & & \\
\hline Female & 2458 & 48.3 & 2717 & 38.5 & & 42,290 & 52.3 \\
\hline Male & 2631 & 51.7 & 4350 & 61.5 & & 38,618 & 47.7 \\
\hline Age (years) & & & & & $<0.001$ & & \\
\hline $0-39$ & 60 & 1.2 & 489 & 6.9 & & 1841 & 2.3 \\
\hline $40-49$ & 113 & 2.2 & 437 & 6.2 & & 1728 & 2.1 \\
\hline $50-59$ & 367 & 7.2 & 882 & 12.5 & & 4291 & 5.3 \\
\hline 60-69 & 887 & 17.4 & 1494 & 21.1 & & 9975 & 12.3 \\
\hline $70-79$ & 1115 & 21.9 & 1423 & 20.1 & & 15,053 & 18.6 \\
\hline $80-89$ & 1673 & 32.9 & 1620 & 22.9 & & 29,360 & 36.3 \\
\hline $90+$ & 874 & 17.2 & 722 & 10.2 & & 18,660 & 23.1 \\
\hline Cause of death ${ }^{b}$ & & & & & $<0.001$ & & \\
\hline Cancer & 2225 & 43.7 & 423 & 6.0 & & 21,913 & 27.1 \\
\hline Circulatory & 2071 & 40.7 & 2173 & 30.7 & & 25,004 & 30.9 \\
\hline Respiratory & 602 & 11.8 & 350 & 5.0 & & 8212 & 10.2 \\
\hline Neurological & 155 & 3.0 & 48 & 0.7 & & 1819 & 2.2 \\
\hline Renal & 36 & 0.7 & 16 & 0.2 & & 489 & 0.6 \\
\hline Other & 0 & 0.0 & 4057 & 57.4 & & 23,471 & 29.0 \\
\hline Household & & & & & $<0.001$ & & \\
\hline Cohabiting & 2273 & 44.7 & 958 & 13.6 & & 33,890 & 41.9 \\
\hline Living alone & 2366 & 46.5 & 1672 & 23.7 & & 28,540 & 35.3 \\
\hline Missing ${ }^{c}$ & 450 & 8.8 & 4437 & 62.8 & & 18,478 & 22.8 \\
\hline Municipality population & & & & & $<0.001$ & & \\
\hline $0-2000$ & 175 & 3.4 & 250 & 3.5 & & 2787 & 3.4 \\
\hline $2001-5000$ & 651 & 12.8 & 809 & 11.4 & & 8972 & 11.1 \\
\hline $5001-10,000$ & 826 & 16.2 & 969 & 13.7 & & 11,109 & 13.7 \\
\hline $10,001-50,000$ & 2092 & 41.1 & 2748 & 38.9 & & 31,091 & 38.4 \\
\hline $50,001-$ & 1337 & 26.3 & 2266 & 32.1 & & 26,664 & 33.0 \\
\hline Missing ${ }^{c}$ & 8 & 0.2 & 25 & 0.4 & & 285 & 0.4 \\
\hline Municipality centrality & & & & & $<0.001$ & & \\
\hline Least central & 647 & 12.7 & 884 & 12.5 & & 9856 & 12.2 \\
\hline Less central & 377 & 7.4 & 481 & 6.8 & & 5582 & 6.9 \\
\hline Somewhat central & 1071 & 21.0 & 1360 & 19.2 & & 15,429 & 19.1 \\
\hline Central & 2986 & 58.7 & 4317 & 61.1 & & 49,756 & 61.5 \\
\hline Missing ${ }^{c}$ & 8 & 0.2 & 25 & 0.4 & & 285 & 0.4 \\
\hline Nursing home ${ }^{d}$ & & & & & $<0.001$ & & \\
\hline Yes & 860 & 16.9 & 549 & 7.8 & & 46,638 & 57.6 \\
\hline No & 4229 & 83.1 & 6518 & 92.2 & & 34,270 & 42.2 \\
\hline Domiciliary care ${ }^{d}$ & & & & & $<0.001$ & & \\
\hline Yes & 5089 & 100.0 & 1966 & 27.8 & & 39,445 & 48.8 \\
\hline No & 0 & 0.0 & 5101 & 72.2 & & 41,463 & 51.2 \\
\hline
\end{tabular}

a $P$ Pearson chi-square test for planned and unplanned home deaths

${ }^{\mathrm{b}}$ Cause of death was divided into five categories according to diagnoses most likely to receive palliative care, the rest were labelled other 'Not included in statistical analysis

dService any time in the period 0-90 days before death 
Table 4 Odds ratio (OR) for potentially planned home death compared with unplanned home death ${ }^{\text {a }}$

\begin{tabular}{|c|c|c|c|c|c|c|c|c|c|}
\hline & \multicolumn{3}{|c|}{ Unadjusted } & \multicolumn{3}{|l|}{ Model 1} & \multicolumn{3}{|l|}{ Model 2} \\
\hline & OR & $\mathrm{Cl}$ & $p$ & Adjusted OR & $\mathrm{Cl}$ & $p$ & Adjusted OR & $\mathrm{Cl}$ & $p$ \\
\hline \multicolumn{10}{|l|}{ Sex } \\
\hline Female & 1.50 & $(1.39,1.61)$ & $<0.001$ & 1.29 & $(1.20,1.40)$ & $<0.001$ & 0.90 & $(0.81,0.99)$ & 0.039 \\
\hline Male & Ref. & & & Ref. & & & Ref. & & \\
\hline \multicolumn{10}{|l|}{ Age } \\
\hline 0-39 & 0.12 & $(0.09,0.16)$ & $<0.001$ & 0.14 & $(0.11,0.18)$ & $<0.001$ & 0.19 & $(0.13,0.26)$ & $<0.001$ \\
\hline $40-49$ & 0.25 & $(0.20,0.31)$ & $<0.001$ & 0.29 & $(0.23,0.37)$ & $<0.001$ & 0.41 & $(0.31,0.54)$ & $<0.001$ \\
\hline $50-59$ & 0.40 & $(0.35,0.46)$ & $<0.001$ & 0.46 & $(0.40,0.53)$ & $<0.001$ & 0.71 & $(0.59,0.87)$ & 0.001 \\
\hline $60-69$ & 0.57 & $(0.52,0.64)$ & $<0.001$ & 0.65 & $(0.58,0.72)$ & $<0.001$ & 1.26 & $(1.07,1.48)$ & 0.005 \\
\hline $70-79$ & 0.76 & $(0.68,0.84)$ & $<0.001$ & 0.82 & $(0.74,0.91)$ & $<0.001$ & 1.32 & $(1.14,1.52)$ & $<0.001$ \\
\hline $80-89$ & Ref. & & & Ref. & & & Ref. & & \\
\hline $90+$ & 1.17 & $(1.04,1.32)$ & 0.009 & 1.10 & $(0.97,1.25)$ & 0.122 & 0.80 & $(0.70,0.92)$ & 0.002 \\
\hline \multicolumn{10}{|c|}{ Municipality population } \\
\hline $0-2000$ & 1.19 & $(0.97,1.46)$ & 0.102 & 1.29 & $(1.02,1.64)$ & 0.032 & 1.40 & $(1.01,1.95)$ & 0.043 \\
\hline $2001-5000$ & 1.36 & $(1.21,1.54)$ & $<0.001$ & 1.36 & $(1.17,1.58)$ & $<0.001$ & 1.40 & $(1.15,1.71)$ & 0.001 \\
\hline $5001-10,000$ & 1.44 & $(1.29,1.62)$ & $<0.001$ & 1.46 & $(1.28,1.67)$ & $<0.001$ & 1.47 & $(1.22,1.75)$ & $<0.001$ \\
\hline $10,001-50,000$ & 1.29 & $(1.18,1.41)$ & $<0.001$ & 1.27 & $(1.15,1.40)$ & $<0.001$ & 1.27 & $(1.12,1.44)$ & $<0.001$ \\
\hline $50,001-$ & Ref. & & & Ref. & & & Ref. & & \\
\hline \multicolumn{10}{|l|}{ Municipality centrality } \\
\hline Least central & 1.06 & $(0.95,1.18)$ & 0.321 & 0.85 & $(0.74,0.99)$ & 0.031 & 0.94 & $(0.78,1.15)$ & 0.570 \\
\hline Less central & 1.13 & $(0.98,1.31)$ & 0.086 & 0.99 & $(0.85,1.16)$ & 0.923 & 1.02 & $(0.82,1.26)$ & 0.868 \\
\hline Somewhat central & 1.14 & $(1.04,1.25)$ & 0.006 & 0.99 & $(0.89,1.10)$ & 0.877 & 0.99 & $(0.86,1.14)$ & 0.904 \\
\hline Central & Ref. & & & Ref. & & & Ref. & & \\
\hline \multicolumn{10}{|l|}{ Nursing home } \\
\hline Yes & 2.44 & $(2.18,2.73)$ & $<0.001$ & 2.00 & $(1.78,2.25)$ & $<0.001$ & 0.78 & $(0.68,0.88)$ & $<0.001$ \\
\hline No & Ref. & & & Ref. & & & Ref. & & \\
\hline \multicolumn{10}{|l|}{ Household } \\
\hline Cohabiting & 1.68 & $(1.52,1.85)$ & $<0.001$ & & & & 1.62 & $(1.46,1.80)$ & $<0.001$ \\
\hline Living alone & Ref. & & & & & & Ref. & & \\
\hline
\end{tabular}

anadjusted, adjusted model 1 for all home deaths $(n=12,123)$ and adjusted model 2 for persons who had received municipal care $(n=7261)$

the proportion of potentially planned home deaths is even lower in Norway than our final estimation $(41.9 \%$ of home deaths and $6.3 \%$ of all deaths), as palliative care is mostly given to people with cancer $[22,26]$.

Most research regarding planned home deaths are interventions trying to enable more home deaths, with little data on the actual rate of planned home deaths before the intervention [27]. We found that only $49 \%$ of home deaths from 'Circulatory disease' were potentially planned, while $84 \%$ of home deaths from 'Cancer' were potentially planned. This indicates a large proportion of sudden or unexpected home deaths from 'Circulatory disease', but could also indicate inequality between these groups in recognition of palliative care needs [28, 29].

\section{Comparison with previous research}

Previous studies have shown that the proportion of home deaths is associated with low functional status, preferences on place of death, home care and its intensity, living with relatives, extended family support, home palliative care, not living in urban areas, higher socio-economic status and being male [8, 14, 16, 25]. Other factors influencing home death are culture, ethnicity and number of hospital and nursing home beds. The relationship with age is more complicated $[8,14,16,25]$.

We found that living alone was associated with more home death. This should be interpreted with caution as we had a large proportion of missing data, but could indicate a large proportion of unexpected home deaths 
for people living alone. However, in a subpopulation of people who had received municipal care, potentially planned home deaths were associated with living together with someone.

There is no consensus definition on rurality, but there is consistency in associations with place of death across definitions [30]. We did not find any association with our definition of rural areas [21], but municipalities with fewer inhabitants were associated with more home death compared to hospital and also with more potentially planned home deaths. This indicates that other factors than travelling distance to hospitals influence proportion of home deaths. Home nursing coverage could be a contributing factor, as smaller municipalities in Norway have better home nursing coverage than larger municipalities. The largest cities have higher coverage of longterm care in institutions and the lowest coverage of home nursing, which could shift end-of-life care to nursing homes instead of home [31].

Our results also showed that fewer women died at home than men. The association was significant when compared to nursing home, similar to a Swedish study [9]. A possible explanation could be that women care for their spouses and live longer, but the association was present also after adjusting for age and living together with someone. Another explanation could be that men have more sudden and unexpected home deaths, as only men had home deaths from external causes of death or symptoms/signs/ill-defined and more unplanned home deaths from circulatory disease. Still, men had higher odds of a potentially planned home death in the subpopulation who had received municipal care.

Like many other countries, Norway has experienced declining home death rates and a shift from hospital to nursing home deaths $[6,8,14]$. This is partly due to population aging but also end-of-life care policy $[2-4,6]$. Incongruence between preferred and actual place of death is common, especially for people with non-malignant disease [29]. Dying in their preferred place is considered a quality indicator of care, and should together with evidence that a majority of people prefer to die at home, be reflected in future planning of palliative care services [1,32].

Transitions in the last phase of life is another important factor to consider when evaluating quality of end-of-life care. Transitions in the last months and days before death are common, with more than half of dying people having at least one transition [33, 34]. Transitions are shown to be more common in home-dwelling people, where about half have a final transition from home to hospital [33, 34]. Groff et al. found an inverse relationship between number of days in domiciliary care and days spent at home in the last six months before death, interpreted as doing more of one thing led to doing more in other areas as well, and did not necessarily improve patient-centred goals [35]. Although home death will never be a goal or possible for all dying people, a more person-centred goal like "days spent at home" could change the perspective of both the dying person and caregivers and lead to increased time spent at home in the final phase of life, and together with palliative homecare reduce symptom burden and increase chances of home death according to the person's own wishes $[27,36,37]$.

\section{Conclusions}

This registry based study from Norway shows that home death is relatively infrequent, and by an indirect algorithm-based definition, we have shown that less than half of them are potentially planned home deaths. Future research should investigate how many deaths that are actually planned to take place at home, and the achievement of this goal. There is also a need to understand the transitions in the last phase of life and whether the place of death corresponds to the patients' wish, and how palliative homecare influences such outcomes.

\section{Abbreviations}

EU Shortlist: European Shortlist for Causes of Death; RRR: Relative risk ratio; IPLOS: National registry for statistics on municipal health and care services; NCoDR: Norwegian Cause of Death Registry

\section{Acknowledgements}

We thank the NCODR and IPLOS for providing us with data, and the Centre for Elderly and Nursing Home Medicine, University of Bergen, for providing a scientific environment.

\section{Funding}

The author(s) disclosed receipt of the following financial support for the research, authorship and/or publication of this article: Epidemiology of home death in Norway is supported by the Department of Global Health and Primary Care at the University of Bergen, the G.C. Rieber Foundation and National Centre for Emergency Primary Health Care, Uni Research Health.

\section{Availability of data and materials}

Data in this study was accessed through linkage of data from the Norwegian Cause of Death Registry at the Norwegian Institute of Public Health (https:// www.fhi.no) and IPLOS at the Norwegian Directorate of Health (https:// helsedirektoratet.no/iplos-registeret). Release of data to researchers requires approval from the Regional Committee for Medical and Health Research Ethics (https://helseforskning.etikkom.no/), the Norwegian Data Protection Authority through the Norwegian Centre for Research Data (http:// www.nsd.uib.no) and from the respective registries.

\section{Authors' contributions}

CK performed study procedures, analysis of data and was responsible for drafting and editing of the manuscript. SH participated in the conception and design of the study, interpretation of the data, and took part in drafting and editing the manuscript. HS participated in the analysis and interpretation of the data and revising the manuscript. BSH participated in the conception and design of the study and revising the manuscript. EF participated in the conception and design of the study and revising the manuscript. All authors read and approved the final manuscript.

\section{Ethics approval and consent to participate}

The study was approved by the Regional Committee for Medical and Health Research Ethics North (2014/2308) and the Norwegian Data Protection Authority (15/00450-2/CGN, 17/00341-3/SBO). Informed consent was not possible. 


\section{Competing interests}

The authors declare that they have no competing interests.

\section{Publisher's Note}

Springer Nature remains neutral with regard to jurisdictional claims in published maps and institutional affiliations.

\section{Author details}

'Research Group for General Practice, Department of Global Public Health and Primary Care, University of Bergen, PO box 7804, N-5018 Bergen, Norway. ${ }^{2}$ Centre for Elderly and Nursing Home Medicine, Department of Global Public Health and Primary Care, University of Bergen, PO box 7804 N-5018 Bergen, Norway. ${ }^{3}$ Bergen Municipality, Bergen, Norway. ${ }^{4}$ National Centre for Emergency Primary Health Care, Uni Research Health, Kalfarveien 31, N-5018 Bergen, Norway. ${ }^{5}$ Department of Clinical Psychology, University of Bergen, PO box 7804, N-5018 Bergen, Norway.

Received: 24 January 2018 Accepted: 23 April 2018 Published online: 02 May 2018

\section{References}

1. Gomes B, Calanzani N, Gysels M, Hall S, Higginson IJ. Heterogeneity and changes in preferences for dying at home: a systematic review. BMC Palliat Care. 2013;12:7.

2. Gomes B, Calanzani N, Higginson IJ. Reversal of the British trends in place of death: time series analysis 2004-2010. Palliat Med. 2012;26:102-7.

3. Wilson DM, Truman CD, Thomas R, Fainsinger $R$, Kovacs-Burns K, Froggatt $K$, Justice C. The rapidly changing location of death in Canada, 1994-2004. Soc Sci Med. 2009;68:1752-8.

4. Teno JM, Gozalo PL, Bynum JW, et al. Change in end-of-life care for medicare beneficiaries: site of death, place of care, and health care transitions in 2000, 2005, and 2009. JAMA. 2013:309:470-7.

5. Norwegian Institute of Public Health. Table D3 - Deaths by place of death. In: Norwegian Cause of Death Registry. 2015. http://statistikkbank.fhi.no/dar/. Accessed 11 Aug 2017

6. Kalseth J, Theisen OM. Trends in place of death: the role of demographic and epidemiological shifts in end-of-life care policy. Palliat Med. 2017:31:964-74

7. Morin L, Aubry R, Frova L, MacLeod R, Wilson DM, Loucka M, et al. Estimating the need for palliative care at the population level: a crossnational study in 12 countries. Palliat Med. 2017;31:526-36.

8. Dasch B, Blum K, Gude P, Bausewein C. Place of death: trends over the course of a decade: a population-based study of death certificates from the years 2001 and 2011. Dtsch Arztebl Int. 2015;112:496-504

9. Hakanson C, Ohlen J, Morin L, Cohen J. A population-level study of place of death and associated factors in Sweden. Scand J Public Health. 2015;43:744-51.

10. Jarlbaek L. Dødssted i Danmark 2012-2014 - relateret til dødsårsager, alder, køn, regioner og kommuner. Report no. 4. In: REPHA, Videncenter for Rehabilitering og Palliation. 2017. http:/www.rehpa.dk/wp-content/uploads/2017/06/2017-4 D\%C3\%B8dssted-DK-2012-2014-final.pdf. Accessed 28 Nov 2017.

11. Cohen J, Pivodic L, Miccinesi G, Onwuteaka-Philipsen BD, Naylor WA, Wilson DM, et al. International study of the place of death of people with cancer: a population-level comparison of 14 countries across 4 continents using death certificate data. Brit J Cancer. 2015:113:1397-404.

12. Houttekier D, Cohen J, Surkyn J, Deliens L. Study of recent and future trends in place of death in Belgium using death certificate data: a shift from hospitals to care homes. BMC Public Health. 2011;11:228.

13. Reich $\mathrm{O}$, Signorell A, Busato A. Place of death and health care utilization for people in the last 6 months of life in Switzerland: a retrospective analysis using administrative data. BMC Health Serv Res. 2013:13:116.

14. Black H, Waugh C, Munoz-Arroyo R, Carnon A, Allan A, Clark D, et al. Predictors of place of death in south West Scotland 2000-2010: retrospective cohort study. Palliat Med. 2016;30:764-71.

15. Gisquet $E$, Julliard $\mathrm{S}$, Geoffroy-Perez B. Do social factors affect the place of death? Analysis of home versus institutional death over 20 years. J Public Health (Oxt). 2016;38:e472-9.

16. Cohen J, Houttekier D, Onwuteaka-Philipsen B, Miccinesi G, AddingtonHall J, Kaasa S, et al. Which patients with cancer die at home? A study of six European countries using death certificate data. J Clin Oncol. 2010;28:2267-73.
17. Pedersen $A G$, Ellingsen $C L$. Data quality in the causes of death registry. Tidsskr Nor Laegeforen. 2015;135:768-70.

18. Norwegian Directorate of Health. IPLOS-registeret. Veileder for personell i kommunale helse- og omsorgstjenester. In: Guideline IS-1112. 2015. https:// helsedirektoratet.no/retningslinjer/iplos-veileder-for-personell-i-kommunalehelse-og-omsorgstjenester. Accessed 2 Jun 2017.

19. Mørk EB, S; Haugstveit, FV; Sundby, B; Karlsen, H; Wettergreen, J. Kommunale helse- og omsorgstjenester 2016. In: Report Statistics Norway. Statistikk om tjenester og tjenestemottakere. 2017. https:// www.ssb.no/helse/artikler-og-publikasjoner/kommunale-helse-ogomsorgstjenester-2016. Accessed 1 Des 2017.

20. Infrastructre Knowledge Base in Europe (INSPIRE). European shortlist for causes of death. In: 2012; 2012. http://inspire.ec.europa.eu/document/CoD. Accessed 9 Aug 2017

21. Statistics Norway. Variabeldefinisjon: Sentralitet. 1994. https://www.ssb.no/a/ metadata/conceptvariable/vardok/927/nb. Accessed 17 Oct 2017.

22. Melby L, Das A, Halvorsen T, Steihaug S. Evaluering av tjenestetilbudet til personer med behov for lindrende behandling og omsorg in: report for the Norwegian Directorate of Health. Report no. A27799. In: SINTEF; 2017. http://www.sintef.no/globalassets/sintef-teknologi-og-samfunn/avdelinger/ helse/20.3.17-rapport-lindrende-behandling_revidert-i-versjonsbeskrivelseog-i-5.2-002.pdf. Accessed 13 Oct 2017.

23. Norwegian Institute of Public Health. Halvparten av oss dør i sykehjem. 2016. https://www.fhi.no/nyheter/2016/halvparten-av-oss-dor-i-sykehjem/. Accessed 17 Oct 2017.

24. Maetens A, De Schreye R, Faes K, Houttekier D, Deliens L, et al. Using linked administrative and disease-specific databases to study end-of-life care on a population level. BMC Palliat Care. 2016;15:86.

25. Higginson IJ, Sarmento VP, Calanzani N, Benalia H, Gomes B. Dying at home-is it better: a narrative appraisal of the state of the science. Palliat Med. 2013:27:918-24.

26. Cohen J, Beernaert K, Van den Block L, Morin L, Hunt K, Miccinesi G, et al. Differences in place of death between lung cancer and COPD patients: a 14-country study using death certificate data. NPJ Prim Care Respir Med. 2017:27:14.

27. Gomes B, Calanzani N, Curiale V, McCrone P, Higginson IJ. Effectiveness and Cost-effectiveness of home palliative care services for adults with advanced illness and their caregivers. Cochrane Database Syst Rev. 2013;6:CD007760.

28. Gadoud A, Kane E, Macleod U, Ansell P, Oliver S, Johnson M. Palliative care among heart failure patients in primary care: a comparison to cancer patients using English family practice data. PLoS One. 2014;9:e113188.

29. Billingham MJ, Billingham SJ. Congruence between preferred and actual place of death according to the presence of malignant or non-malignant disease: a systematic review and meta-analysis. BMJ Support Palliat Care. 2013;3:144-54.

30. Rainsford S, MacLeod RD, Glasgow NJ. Place of death in rural palliative care: a systematic review. Palliat Med. 2016;30:745-63.

31. Otnes $\mathrm{BH}$, Haugstveit FV. Kommunal variasjon i omsorgstjenester. In Report Statistics Norway Report no 2015/44. 2015. https://www.ssb.no/helse/artikler-ogpublikasjoner/kommunal-variasjon-i-omsorgstjenester. Accessed 1 April 2018.

32. De Roo ML, Miccinesi G, Onwuteaka-Philipsen BD, Van Den Noortgate N, Van den Block L, Bonacchi A, et al. Actual and preferred place of death of home-dwelling patients in four European countries: making sense of quality indicators. PLoS One. 2014:9:e93762.

33. Van den Block L, Pivodic L, Pardon K, Donker G, Miccinesi G, Moreels S, et al Transitions between health care settings in the final three months of life in four EU countries. Eur J Pub Health. 2015:25:569-75.

34. Abraham S, Menec $V$. Transitions between care settings at the end of life among older homecare recipients: a population-based study. Gerontol Geriatr Med. 2016;2:2333721416684400

35. Groff AC, Colla CH, Lee TH. Days spent at home - a patient-centered goal and outcome. N Engl J Med. 2016;375:1610-2.

36. Sayer C. NEJM Catalyst. In: "Time spent at home" - a patient-defined outcome; 2016. https://catalyst.nejm.org/time-spent-at-home-a-patientdefined-outcome/. Accessed 10 Nov 2017.

37. Costa V, Earle CC, Esplen MJ, Fowler R, Goldman R, Grossman D, et al. The determinants of home and nursing home death: a systematic review and meta-analysis. BMC Palliat Care. 2016;15:8. 